Article

\title{
Past Management Spurs Differential Plant Communities within a Giant Single-Clone Aspen Forest
}

\author{
Paul C. Rogers ${ }^{1, *}$ and Jan Šebesta ${ }^{2}$ \\ 1 Western Aspen Alliance, Wildland Resources Department, and Ecology Center, Utah State University, Logan, \\ UT 84322, USA \\ 2 Faculty of Forestry and Wood Technology, Department of Forest Botany, Dendrology, and Geobiocoenology, \\ Mendel University, 63800 Brno, Czech Republic; sebestian.cz@gmail.com \\ * Correspondence: p.rogers@usu.edu; Tel.: +1-435-797-0194
}

Received: 12 October 2019; Accepted: 6 December 2019; Published: 7 December 2019

check for updates

\begin{abstract}
Sustainable aspen ecosystems hold great promise for global biodiversity conservation. These forests harbor relatively high species diversity, yet are threatened by fire suppression, land development, timber-focused management, extended droughts, and chronic herbivory. "Pando" is a high-profile quaking aspen (Populus tremuloides) forest in Utah, USA which is putatively the 'largest living organism on earth.' Pando comprises an estimated 47,000 genetically identical stems, but is threatened by human impacts. Our interest in the present study is whether changes to the giant organism were affecting understorey vegetation and whether discrete zones are displaying divergent community compositions. For instance, recent research has demonstrated strong herbivory impacts that are affecting portions of Pando differentially. This study consists of 20 randomly distributed vegetation survey plots within three de facto management regimes (hereafter, management group or type) along an herbivory protection gradient: No Fence, 2013 Fence (total protection), and 2014 Fence (imperfect protection). The plant survey was supplemented by previously-established forest and herbivore measurements to test for community assemblage explanatory agents. Sixty-eight species were found across the entire study. Analyses indicated strong links between management group orientation, species assemblages, and tree density/canopy openings. We found distinct evidence that within management group species composition was more similar than across groups for two of the three pairings. However, the other pairing, the most successfully protected area and the completely unprotected area, was not statistically distinct; likely a result a deteriorating overstorey in these two areas, whereas the third management type (2014 Fence) exhibited higher canopy cover. Indicator species analysis found that a small group of plant species had statistical allegiances to specific management groups, suggesting resource preference selection within Pando. Ordination analysis searching for causal factors reached two broad conclusions: (1) aspen regeneration, and therefore long-term resilience, is being negatively affected by chronic animal browsing and (2) current understorey species diversity is highest where forest canopy gaps are abundant. Future research at the massive Pando clone will continue informing linkages between understorey communities and overstorey-driven ecological pathways.
\end{abstract}

Keywords: understorey vegetation; Populus tremuloides; regeneration; herbivory; ungulates; ordination; indicator species; community ecology; trembling aspen; biodiversity

\section{Introduction}

Increasingly, forest ecology and management is concerned with ripple effects of process-based strategies as they apply to not only primary forest cover, but to dependent species along trophic 
vectors. Quaking aspen (Populus tremuloides), henceforth "aspen," forests exhibit enormous ecological amplitude across the North American continent. As a very widespread species, we often overlook their important contributions to biological diversity, perhaps assuming that all aspen ecosystems are similar and therefore display little compositional variation. In fact, numerous researchers have established key functional distinctions in aspen, which stands to reason within a species ranging across very broad ecological zones [1-4]. A central distinction among aspen functional types is their relative dependence on wildfire for stand rejuvenation [5]. Whereas seral aspen readily regenerate, predominantly through asexual root suckering following wildfire, stable (also known as pure or persistent) aspen are rarely subjected to fire at all, thus their reproductive periodicity favors continuous rather than episodic regeneration [6]. These distinctions are important when restorative actions are undertaken in a management framework focused on ecologically appropriate emulation of key processes [4]. Forest management that runs counter to driving functional processes is often doomed to futility and failure $[7,8]$.

An important feature of aspen forests is their contribution to landscape-level biodiversity. Aspen in the Rocky Mountain West, USA, are second only to riparian areas among forest types in harboring the most species [9-11]. For this reason, some authors have denoted aspen, both in North America and Europe, as a keystone species [12-15]. While these communities provide habitat for a great number of species-both animals and plants-their often-cited declining condition $[10,16,17]$ is expected to reduce landscape- and perhaps regional-level species numbers [18]. Recent works consistently point to ungulate herbivory as a prime driver of aspen system degradation [19,20]. Moreover, many authors have noted that declining aspen conditions have cascading impacts on a host of both plant $[18,21,22]$ and animal $[11,23,24]$ functional groups. Within species, genetic diversity is presumed to enhance resilience across scales [25], as genotype is closely tied to growth, defense, and reproductive capacity [26]. We know little, however, of how understorey plant assemblages might react over time to habitat changes within large clonally uniform forest communities. While one might anticipate generally synchronous responses across large clones, this may be much more difficult to predict where direct and indirect human management decisions potentially lead areas within such clones on diverging ecological pathways.

A large, genetically uniform, aspen clone known as Pando (Latin: I spread) lives on the Sevier Plateau in south-central Utah, USA. The 43 ha clone was first identified in the late 1960s by researchers testing the hypothesis that individual aspen clones could be differentiated by physical plant structures alone [27]. Later, another research group advanced the 'world's largest organism' label and named the clone Pando, thus drawing public and scientific attention to this unique single clone forest [28]. Confirmation of Pando's size and uniform genetic make-up using modern microsatellite molecular techniques took place several years later [29], though this finding was synchronous with increasing concern for the apparent decline of the clone. Recent systematic research has not only elevated attention to Pando's rapid overstorey mortality, but more importantly to the cessation of successful reproduction-save a single fenced exclosure amounting to $<20$ percent of the massive clone [30]. While it is clear the base cause of the current trajectory is not mature tree mortality, but chronic browsing of regenerating aspen suckers, we are left wondering how this iconic organism survived and thrived likely for millennia-the exact age is unknown-while it appears to be dwindling suddenly during our time. Changes in ungulate herbivore management over recent decades provides the most plausible explanation [31], though exacerbating agents, such as increased human presence and warming/drying climatic conditions likely play a role. Collectively, both direct and indirect human impacts are negatively influencing Pando. Having established that Pando is undergoing dramatic change, it follows that dependent plant communities may benefit or falter in tandem with these developments, although concerted research has yet to take on this question.

Aspen, as a keystone species, and Pando being an exemplar of potential species/community size and uniformity, presents a unique opportunity to explore patterns of plant diversity under changing forest dynamics. Our base objective was to understand the management regimes at Pando as expressed 
through understorey plant communities. We approached this is a stepwise fashion, building from group status, to identifying indicators species, to probing casual factors or key ecological gradients. In this manner, the current work used exploratory methods in community ecology to identify key descriptors of Pando's vegetation status. In order to accomplish this task, we developed a complementary study protocol focused on identifying and assessing plant community make-up as it pertains to forest cover, aspen recruitment, and browsing impacts in this unique setting. The following questions, therefore, constituted the central focus of the current study. (1) Are there group differences in understorey composition between management regimes which may indicate potential diverging pathways? (2) Do individual understorey species display preference for de facto management regimes within the Pando clone? (3) What are the key factors (gradients) underlying plant species diversity? (4) Do some plant species exhibit preference for the most prominent explanatory gradients? Depending on results, the first two questions may lead us to ponder whether diverging understorey assemblages at Pando require key ecological linkages which may now be severed within this genetically uniform forest overstorey. Our expectation is that this massive overstorey clone would support closely aligned plant communities throughout its extent, particularly in a setting such as Pando where elevation and topography vary only modestly (Supplementary material, Table S1). Determination of causal factors for plant community divergences (or convergences) will aid our understanding of burgeoning and future restoration related to Pando's declining state [30]. Outcomes here are expected to add to broader discussions pertaining to clonally dominant tree systems and their international contributions to biodiversity $[9,21,22,32]$.

\section{Methods}

\subsection{Study Site}

The Pando aspen clone is found on the Fishlake National Forest in south-central Utah (UTM $434701 \mathrm{E}, 4264266 \mathrm{~N})$. The average elevation is $2707 \mathrm{~m}$ and slopes are gentle (0-10 degrees) with a generally southeast aspect. Soils are mixed gravelly and cobbly in both loamy A-horizons and clayey B-horizons (Draft Survey, Fishlake National Forest, National Cooperative Soil Survey UT651) originating from tertiary volcanic materials. The forest floor is modestly vegetated, with ample exposed volcanic boulders and bare ground patches. Common juniper (Juniperus communis) and mountain big sagebrush (Artemisia tridentata) are common shrubs across the area. Annual precipitation is attributed mostly to winter snow, with a prominent pulse of summer rainfall (466 mm year ${ }^{-1}$ precipitation, SNOTEL 1149, 6 years. average).

Pando is located near Fish Lake, a popular resort area. An access road bisects Pando and there are camp sites and private summer homes within the clone. These tourist activities provide indirect protection for browsing ungulates, as hunting of game species is prohibited in such popular areas. Small clearfell-coppice cuts were performed near the edge of the clone in 1987 and 1988, but were unfenced. An additional cut within Pando took place in 1992, though managers at that time elected to fence this treatment due to heavy browsing (and consequently complete forest loss) following the earlier cuts. Currently, domestic cattle (Bos spp.) forage at Pando under a U.S. Forest Service grazing allotment for approximately two weeks annually. Mule deer (Odocoileus hemionus) and Rocky Mountain elk (Cervus elaphus) access this area freely during the typically seven-month snow-free season. Elk appear to be absent in the immediate area based on previous scat surveys within the study area, though we know they are common further from areas of elevated human use. Visitors to the area are generally unaware of Pando's reputation as the 'world's largest organism' [28] due to a lack of signage or other interpretive materials. Thus, while Pando is easily accessible from the access roadway, few people intentionally visit the clone and therefore direct human impacts are minimal.

\subsection{Field Methods}

Data collection for the current study took place over a four year period in two basic sampling efforts: a previously-established network of sample plots to assess base forest conditions and the 
current understorey vegetation assessment. The original plot selection was based on a $50 \mathrm{~m}^{2}$ grid of potential sample points with random sub-selection from that matrix. This process resulted in 65 total forest measurement plots across three distinct management regime areas. These areas are referred to as management groups here, although they were not originally designated as experimental zones, but they remain de facto groupings due to the resulting differences in their reproductive success [31]. Those management areas are referred to as: No Fence, 2013 Fence, and 2014 Fence (Box 1; Figure 1). These distinct zones, having previously shown disparate regeneration based on ungulate browsing patterns [31] may also be developing distinct understorey plant communities (the purpose of this study). While the designation No Fence is self-evident, the 2013 Fence (experimental manipulations) and 2014 Fence (no recent manipulations) areas are distinguished not only by recent human disturbance, but by their relative success in protection from browsing. The 2013 Fence was very successful at facilitating aspen regeneration whether plots were disturbed or undisturbed [30], while the 2014 Fence was much less so [31].

Box 1. Treatment Groups.

No Fence-area is unrestricted from browsing herbivores.

2013 Fence-area is restricted from browsing herbivores AND implemented fire, shrub removal, and 50\% overstory tree cutting. Approximately half this area was undisturbed as a control.

2014 Fence-area is restricted from browsing herbivores and no recent disturbance has taken place. A previous study, however, determined that mule deer were entering and browsing aspen suckers (cattle had no access).

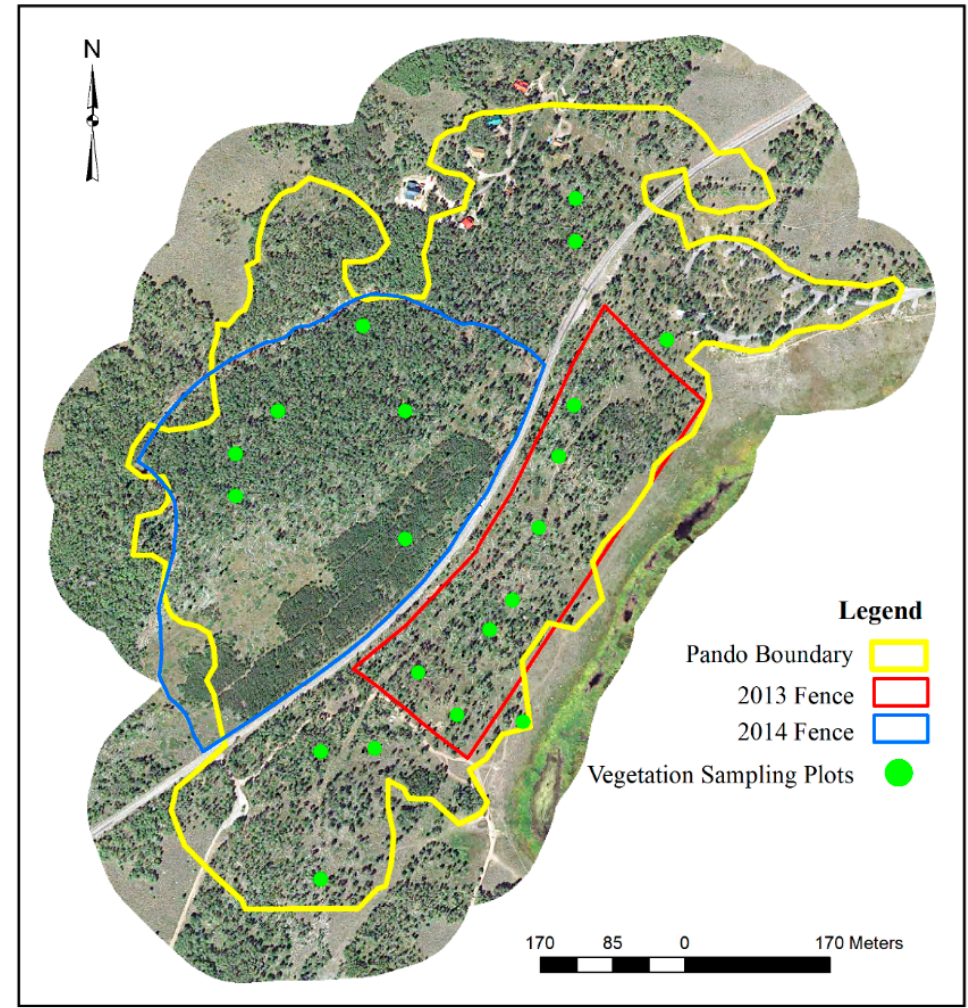

Figure 1. Map depicting the study area within the Pando aspen clone, Utah, USA. Twenty sample plots were randomly distributed across the study area in the following proportions: No Fence (7), 2013 Fence (7), and 2014 Fence (6), representing discrete management regimes. Base image courtesy of Google $\operatorname{Earth}^{\circledR}$ (v. 7.3, Mountain View, CA, USA) 
Each forest mensuration plot consisted of two fixed area transects $(2 \times 30 \mathrm{~m})$ aligned perpendicular to each other to capture terrain deviations which may affect site/growth performance. From 2014-2017 field technicians conducted basic site description, mensuration, and reproduction, browse, and animal scat surveys described in detail by Rogers and Gale [30]. In brief, survey crews measured mature tree diameters at breast height (dbh), tree status (live/dead), number of aspen suckers within height groups, tree and shrub cover, and percent of browsed suckers. Additionally, we counted ungulate pellet groups within fixed area transects. All site, tree, reproduction, browse, and scat data were summarized as per ha values for analysis.

For the current study, a randomly-selected subset of the complete Pando plot network was used to gather new detailed understorey vegetation. With our current sampling regime, we were unable to sample the full mensuration grid of 65 plots due to time and expertise limitations. On 20 plots distributed across the three management zones we identified all plant species and estimated their cover using a dual collection method following procedures of the U.S. Forest Service, Forest Health Monitoring program [33]. Species identification and abundance/cover were obtained on three $1 \mathrm{~m}^{2}$ quadrats set at $5 \mathrm{~m}$ from permanent plot center markers at compass readings of $0^{\circ}, 120^{\circ}$, and $240^{\circ}$. An additional timed search of the entire vegetation plot ( $7 \mathrm{~m}$ radius) was conducted for species not previously noted in sample quadrats. This combined small-area (quadrats) and larger timed-survey area (plot) two-step process is thought to yield the most thorough species capture [33,34]. Visual estimates of abundance in small- and large-areas were classified in percent cover groups favoring lower coverage accuracy as follows: $<1,1-5,6-10,11-25,26-50$, and $>50$. Abundance data were pooled by species for total sample plot (i.e., quadrats and large-area) using a standardized algorithm to group total abundance ratings into classes specified above, as per the Forest Health Monitoring technique [33]. All vegetation plots were sampled during June 2018 to take advantage of maximum plant expression prior to mid-to-late summer drying and desiccation. Plants not positively identified in the field were confirmed at the Utah State University Herbarium at a later date. Species data were summarized using standard diversity indices: species richness, species evenness, Shannon's diversity index, and Simpson's diversity index [35]. Nomenclature throughout this study followed Welsh et al. [36].

\subsection{Analytical Methods}

Our analytical objective was to comprehensively understand the various management regimes at Pando through the lens of understorey plant communities. We took three distinct analytical approaches: management group differences, individuals species affinity distinctions, and (exploratory) causal factor analysis, which may explain putative differences wrought by management groups. The first two methods employed only plant communities to understand group and species preferences, while the third (causal factor) utilized numerous site, tree, herbivory, and plant community measures. The mechanism for accomplishing this was the PC-ORD (v.7.0, [37]) software package, specifically techniques designed to understand group preferences and explanatory variable "data landscapes" (gradients) using ordination methods [35,37]. In this regard, being a first-time measurement of plant species, data analysis should be considered exploratory in nature (i.e., the study design was not a conventional, hypothesis-driven, framework).

Our initial question was to discern whether species presence and abundance was more similar on plots within management groups as compared to across groups. Multi-response permutation procedures (MRPP) is a nonparametric test for describing within-group agreement of variables in contrast to adjoining data groups. We selected MRPP using the Sørensen distance measure because it is less inclined to exaggeration based on outliers and zero values for cover estimates [38]. All categorical variables were removed from the data matrix except for our group designator, thus this analysis was performed on a matrix of 20 plots by 68 species. MRPP produces a T score indicating the degree of difference between group pairs, an A-value which is the chance-corrected within group agreement (effect size), as well as a $p$-value establishing level of test significance [35]. 
The next analytical question involved individual plant species habitat preferences; do certain species favor one management trajectory over another within this genetically uniform forest? Indicator species analysis (ISA) is a multivariate approach testing for no difference between a priori groups in terms of species affinity, or "faithfulness," based on presence and abundance of taxa within groups [39]. We chose ISA to gain a better understanding of species preferences (if any) for current management regimes at Pando. Perfect affinity is defined as always being present and exclusive in the identified group [35]. The statistical significance of the maximum indicator value for each species was tested by 5000 runs of a Monte Carlo randomization procedure. The resulting $p$-value represents the probability that the calculated indicator value for any species is greater than chance occurrence. Output includes the group for which the maximum indicator value is found, the indicator score for that group, and the associated $p$-value for each species.

Our final goal (questions 3-4) was to seek explanatory gradients within a comprehensive data set encompassing site description, mensuration, regrowth, browsing, animal presence, and understorey species diversity indices. The incorporation of diversity indices, based on all plant species tallied, differentiated this present analysis from past Pando studies addressing primarily regeneration and animal interactions [30,31]. Diversity indices further provided potential plant community-based indicators at the management group level to distinguish broader diversity patterns within this unique landscape. For exploratory analyses of data gradients addressing causal factors we selected nonmetric multi-dimensional scaling (NMS). NMS is an ordination technique suited for ecological questions where multiple data types are used, normal distributions and variances may be absent, and data sets may contain large numbers of zeros [40]. The aim of NMS is to reduce complex multidimensional data sets to a few key explanatory gradients (axes). The primary matrix for this analysis consisted of 20 plots (rows) pitted against 18 sampling variables (columns). A broader suite of 26 field variables was trimmed down by two categories: raw tally scores (e.g., stem counts) that were redundant to per ha values and location variables (location coordinates and elevation) that detracted from ordination analysis due to their small variation (i.e., having little explanatory value). Two secondary matrices of environmental variables and individual species were plotted over main NMS results in a joint plot graph for display purposes. The lowest stress solution was derived from 250 runs with real plot data. "Stress" is defined as a quantitative assessment of final ordination monotonicity, a measure of how well real data fit the ordination $[35,38]$. The lowest stress solution was tested with a Monte Carlo run of an additional 250 randomized iterations to evaluate the probability of the final NMS solution being greater than chance (i.e., yielding a $p$-value). Orthogonal rotation of the final ordination was used to maximize alignment between the strongest environmental variables (i.e., Pearson $r$ values) and primary axes. The lowest number of dimensions (axes) was selected when adding another dimension would have decreased the final stress by $<5$ [35]. Results were for all tests were considered significant where $p<0.05$.

\section{Results}

\subsection{Is Plant Community Composition Different between Groups?}

We recorded a total plant diversity $(\gamma)$ of 68 species, five of which could only be identified to genus, on a total of 20 field plots within the three management regimes of the Pando aspen clone. The average species richness per plot $(\alpha)$ was $23.15(\mathrm{SD}=3.89)$. Beta diversity $(\beta=\alpha / \gamma)$ at 0.34 represents an estimate of "community turnover" or (in this case) a relatively high species overlap among all sample locations at Pando. Supplementary Tables S1 present mean and variance (SD) values for analysis variables, as well as cover and frequency values for common plant species. 
We used multi-response permutation procedures (MRPP) to test for within-group similarity in understorey species composition. Results of this test are shown as an overall score, as well individual pairings of three group combinations (Table 1). Larger negative " $\mathrm{T}$ " scores indicate greater separation (dissimilarity) between groups. " $\mathrm{A}$ " scores signify a chance-corrected within-group agreement score: $1.0=$ perfect agreement, $0=$ no better than expected by chance, and an A value of $>0.3$ is considered a strong indicator of within group species homogeneity [35]. An overall MRPP test result indicates strong within group homogeneity, while comparisons between the 2014 fenced plots and the other two groups also yielded significant within group agreement (Table 1). Understorey vegetation assemblages, when compared between the No Fence and 2013 Fence groups, displayed no significant difference.

Table 1. Multi-response permutation procedures (MRPP) test results for differences in cumulative scores for all plant species presence and cover between management groups. T is the MRPP test statistic which calculates the difference between observed and expected delta. A is the chance-corrected within-group agreement.

\begin{tabular}{cccc}
\hline Management Group & T & A & $p$ \\
\hline No Fence vs. 2013 Fence & -1.29 & 0.06 & 0.100 \\
No Fence vs. 2014 Fence & -2.66 & 0.13 & 0.016 \\
2013 Fence vs. 2014 Fence & -5.58 & 0.29 & $<0.001$ \\
\hline Overall test result & 4.43 & 0.22 & $<0.001$ \\
\hline
\end{tabular}

\subsection{Species Preference for Management Groups}

Of the 68 distinct species represented in our understorey plant survey at Pando only seven showed a solid affinity for particular management groups (Table 2). Indicator species analysis results found that four species met a higher significance threshold $(<0.05 p$-value) for group allegiance. Populus tremuloides (understorey only) and Potentilla hippiana favored the 2013 fenced area and Calamagrostis spp. and Lupinus argenteus were statistically associated with the 2014 fenced group. Additionally, three other species fell just below the significance threshold and were also only statistically aligned with the fenced area survey groups (Table 2). No species showed ISA preference for the No Fence area, suggesting a generalist plant assemblage or perhaps areas without species-specific habitat.

Table 2. Indicator species analysis values for understorey vegetation species tallied by maximum score group ( $1=$ No Fence, $2=2013$ Fence, and $3=2014$ Fence). A subset of all species are shown here to highlight those that displayed clear group preference $(p<0.10)$. Species shown in bold type are those with $p$-values $<0.05$.

\begin{tabular}{cccccc}
\hline \multirow{2}{*}{ Species } & $\begin{array}{c}\text { Maximum } \\
\text { Score Group }\end{array}$ & $\begin{array}{c}\text { Indicator } \\
\text { Value }\end{array}$ & \multicolumn{2}{c}{ Indicator Values from Randomization } \\
\cline { 4 - 6 } & & Mean & Standard Deviation & $p$ \\
\hline Artemisia tridentata & 2 & 50.0 & 35.5 & 8.46 & 0.0684 \\
Populus tremuloides & 2 & 60.6 & 40.0 & 4.51 & 0.0002 \\
Bromus ciliatus & 2 & 42.9 & 18.4 & 9.97 & 0.0814 \\
Calamagrostis spp. & 3 & 70.0 & 28.0 & 9.94 & 0.0040 \\
Lupinus argenteus & 3 & 55.4 & 38.3 & 5.52 & 0.0022 \\
Potentilla hippiana & 2 & 56.2 & 33.9 & 8.69 & 0.0198 \\
Silene menziesii & 3 & 38.9 & 20.5 & 9.49 & 0.0764 \\
\hline
\end{tabular}

\subsection{Exploring Factors Affecting Species Make-Up and Habitat Preferences}

Ordination analysis resulted in a two-dimensional solution on a matrix of 20 plots by 18 variables. We projected the results of the NMS in ordination "plot-data space" as a joint plot highlighting environmental variables as overlay vectors (Figure 2a). The final NMS solution produced a stress value of 8.84 with an instability of 0.00 . A Monte Carlo test of 250 random data runs versus the real data set verified a significant NMS outcome $(p=0.03)$. A two-axis solution described about $87 \%$ of ordination 
variance (axis 1: $r^{2}=0.489$; axis 2: $r^{2}=0.377$; and orthogonality $=99.8$ ). Length and direction of vectors corresponds to environmental variable strength and relationship to the two-dimensional plot-data space. Only environmental variables making the strongest contributions to data ordinations are shown (i.e., $\mathrm{r}^{2} \geq 0.3$ ) in the joint plot (Figure 2a). Table 3 presents NMS results by axes for all environmental variables. Most measures tested in this ordination contributed very little to environmental gradients (NMS axes) at Pando. Strong positive and negative responses to axis 1 (Figure 2a) represent factors working in opposition in terms of their influence on the totality of plot variable values at Pando. Axis 1 describes a gradient of regeneration abundance with a negative correlation to deer and cattle presence. This result is nearly identical to that reported previously [31]. Axis 2 illustrates an inverse correlation between aspen cover (collectively) and understorey species diversity. A moderately strong correlation of aspen recruitment to axis 2 may present a spurious result given the low overall recruitment occurrence among our sample sites (with the exception of a single anomalous plot in a 1992 historic clearfell-coppice cut area [30]). Figure $2 \mathrm{~b}$ projects species vectors as an overlay on the main ordination to gauge how particular plants align with explanatory variables. Only those species with $\mathrm{r}^{2}>0.3$ are shown. While most plants showed no particular statistical relation to prime NMS axes, P. tremuloides, Cirsium clavatum, Festuca thurberi, and Penstemon watsonii displayed robust correlations $(r>0.5$ or $<-0.5)$ to these environmental gradients (Table 4$)$.

Table 3. Pearson's coefficients ( $r$ ) between environmental variables and primary NMS ordination axes. The strongest response variables are highlighted in bold type, where $r>0.5$ or $<-0.5$. Basal area is abbreviated as BA here.

\begin{tabular}{|c|c|c|}
\hline \multirow{2}{*}{ Variable Name } & \multicolumn{2}{|c|}{ r-Value } \\
\hline & Axis 1 & Axis 2 \\
\hline Fence & 0.138 & 0.309 \\
\hline Juniper cover & -0.048 & 0.319 \\
\hline Aspen cover & 0.056 & 0.683 \\
\hline Regeneration $\mathrm{ha}^{-1}$ & 0.656 & -0.101 \\
\hline Browse level & -0.456 & -0.244 \\
\hline Recruitment ha ${ }^{-1}$ & 0.142 & 0.694 \\
\hline Trees ha $\mathbf{a}^{-1}$ & 0.242 & 0.892 \\
\hline Live trees ha $\mathrm{a}^{-1}$ & 0.223 & 0.957 \\
\hline BA live & 0.014 & 0.533 \\
\hline BA dead & -0.111 & 0.319 \\
\hline BA dead as $\%$ total BA & -0.090 & 0.066 \\
\hline BA total & -0.025 & 0.506 \\
\hline Cattle scat & -0.677 & -0.068 \\
\hline Deer scat & -0.770 & 0.020 \\
\hline Species richness & 0.150 & -0.385 \\
\hline Species evenness & -0.504 & -0.185 \\
\hline Shannon's diversity & 0.036 & -0.488 \\
\hline Simpson's diversity & -0.031 & -0.576 \\
\hline
\end{tabular}




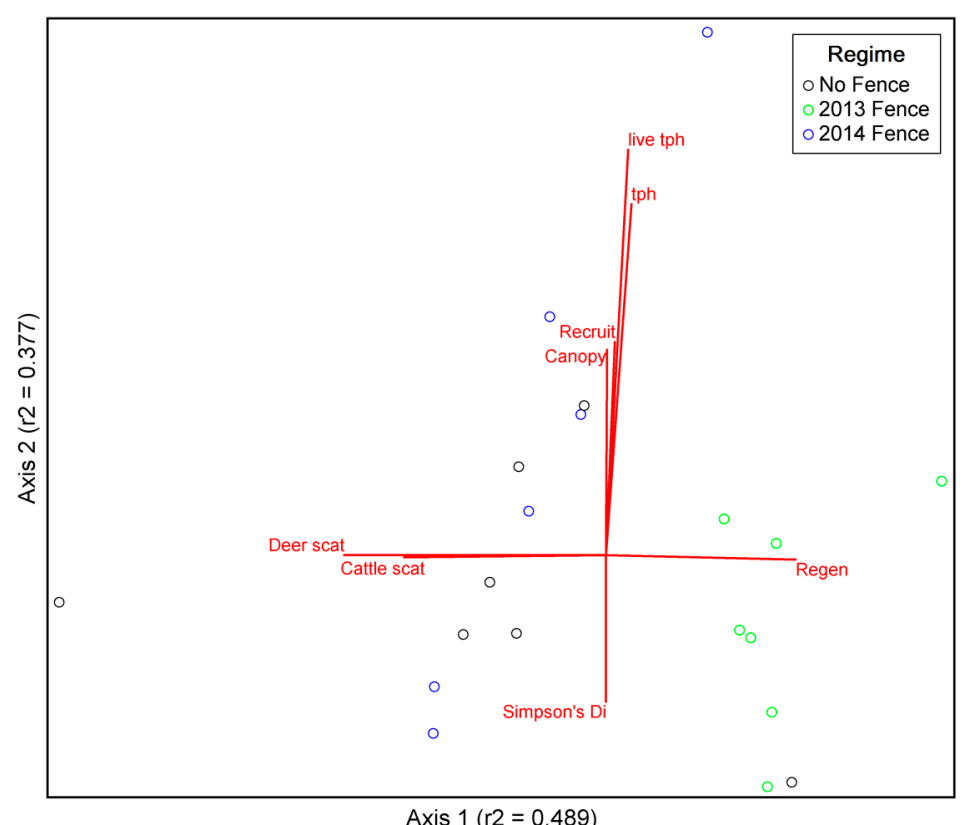

(a)

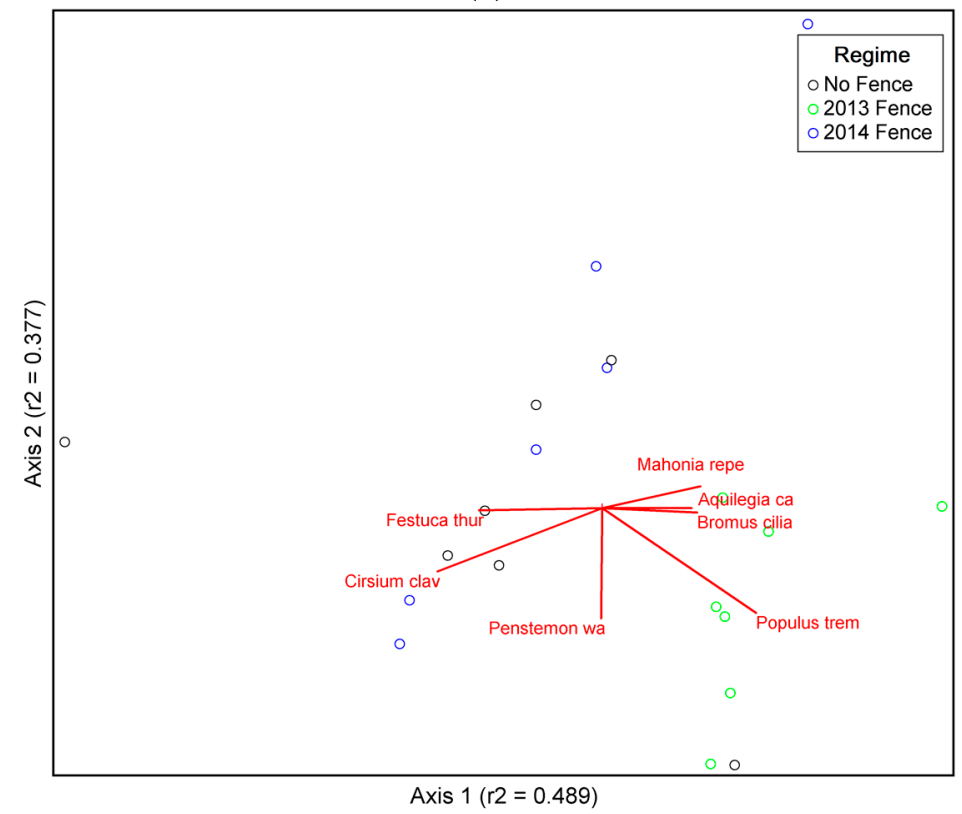

(b)

Figure 2. Joint plots depict the results of nonmetric multidimensional scaling (NMS) ordination on a matrix of 20 plots by 18 monitoring variables. Highly correlated environmental variables $\left(\mathrm{r}^{2} \geq 0.3\right)$ are overlaid on the ordination to show relationships to primary axes. Vectors indicate direction and strength (length) of these factors in the ordination space defined by plot values of all measured variables. (a) Environmental variables having the greatest influence within the total data ordination space. Variables shown: deer scat groups ha ${ }^{-1}$ (Deer scat), cattle scat ha ${ }^{-1}$ (Cattle scat), aspen regeneration stems ha ${ }^{-1}$ (Regenh), aspen recruitment stems ha ${ }^{-1}$ (Recruit), percent aspen cover (Canopy), live mature trees ha ${ }^{-1}$ (live tph), trees ha ${ }^{-1}$ (tph), and Simpson's diversity index (Simpson's Di). Circles depict locations, by regime group, of plot scores in "data space" within the NMS ordination and (b) Hhly correlated $\left(\mathrm{r}^{2} \geq 0.3\right)$ plant species overlayed on the same "data space" NMS ordination as (a). Species are: Festuca idahoensis, Cirsium clavatum, Penstemon watsonii, Populus tremuloides, Bromus ciliatus, Aquilegia caerulea, and Mahonia repens. 
Table 4. Pearson's coefficients (r) between understorey plant species and primary NMS ordination axes. The strongest response variables are highlighted in bold type, where $\mathrm{r}>0.5$ or $<-0.5$.

\begin{tabular}{|c|c|c|c|c|c|}
\hline \multirow{2}{*}{ Species Name } & \multicolumn{2}{|c|}{ r-Value } & \multirow{2}{*}{ Species Name } & \multicolumn{2}{|c|}{ r-Value } \\
\hline & Axis 1 & Axis 2 & & Axis 1 & Axis 2 \\
\hline Abies lasiocarpa & -0.144 & -0.003 & Clematis hirsutissima & 0.250 & -0.120 \\
\hline Amelanchier alnifolia & 0.252 & -0.023 & Comandra umbellata & -0.423 & -0.088 \\
\hline Arctostaphyllos uva-ursi & -0.008 & 0.328 & Cynoglossum officinale & -0.180 & -0.176 \\
\hline Artemisia ludoviciana & -0.082 & 0.141 & Dactylis glomerata & 0.340 & 0.249 \\
\hline Artemisia tridentata & -0.190 & -0.282 & Elymus glaucus & 0.152 & 0.138 \\
\hline Chrysothamnus viscidiflorus & -0.087 & -0.085 & Elymus trachycaulus & -0.058 & 0.035 \\
\hline Juniperus communis & 0.336 & 0.351 & Erigeron sp. & -0.213 & -0.354 \\
\hline Mahonia repens & 0.474 & 0.222 & Eriogonum racemosum & -0.224 & -0.043 \\
\hline Populus tremuloides & 0.592 & -0.488 & Festuca idahoensis & 0.001 & -0.104 \\
\hline Prunus virginiana & -0.144 & -0.003 & Festuca thurberi & -0.530 & -0.075 \\
\hline Ribes montigenum & -0.144 & -0.104 & Fragaria virginiana & 0.167 & -0.396 \\
\hline Ribes inerme & -0.144 & -0.003 & Frasera speciosa & 0.206 & -0.358 \\
\hline Rosa woodsii & -0.076 & -0.171 & Geranium richardsonii & 0.165 & -0.117 \\
\hline Symphoricarpos oreophilus & 0.173 & -0.124 & Hackelia micrantha & 0.337 & 0.182 \\
\hline Agoseris laciniata & -0.237 & -0.124 & Hesperostipa comata & 0.079 & 0.045 \\
\hline Achillea millefolium & -0.040 & -0.205 & Juncus arcticus & -0.190 & -0.064 \\
\hline Achnatheron nelsonii & -0.311 & -0.232 & Koeleria macrantha & -0.379 & 0.135 \\
\hline Allium bisceptrum & -0.250 & -0.184 & Lactuca sp. & -0.286 & -0.136 \\
\hline Antennaria microphylla & 0.074 & -0.242 & $\begin{array}{l}\text { Lithospermum } \\
\text { multiflorum }\end{array}$ & 0.344 & -0.036 \\
\hline Aquilegia caerulea & 0.451 & -0.020 & Lotus wrightii & 0.201 & -0.180 \\
\hline Arabis sp. & 0.157 & -0.250 & Lupinus argenteus & -0.155 & 0.142 \\
\hline Arenaria macrophylla & 0.163 & -0.348 & Penstemon watsonii & -0.038 & -0.502 \\
\hline Astragalus tenellus & 0.258 & -0.129 & Poa fendleriana & 0.171 & -0.134 \\
\hline Astragalus laxmannii & 0.140 & -0.134 & Poa pratensis & 0.111 & -0.064 \\
\hline Bromus ciliatus & 0.464 & -0.098 & Potentilla hippiana & -0.081 & -0.318 \\
\hline Bromus inermis & -0.040 & -0.010 & Senecio streptentifolius & 0.416 & -0.179 \\
\hline Calamagrostis sp. & -0.062 & 0.217 & Silene menziesii & 0.100 & 0.204 \\
\hline Carex douglasii & -0.065 & -0.079 & Smilacina stellata & -0.098 & 0.182 \\
\hline Carex obtusata & 0.171 & -0.124 & Taraxacum officinale & -0.205 & -0.169 \\
\hline Carex occidentalis & -0.082 & 0.080 & Thalictrum fendlerii & -0.073 & 0.298 \\
\hline Carex rossii & 0.228 & -0.112 & Thermopsis montana & 0.174 & -0.074 \\
\hline Carex tahoensis & -0.237 & -0.124 & Tragopogon dubius & 0.148 & 0.015 \\
\hline Castilleja sp. & 0.157 & -0.250 & Viola adunca & 0.104 & 0.132 \\
\hline Cirsium clavatum & -0.613 & -0.381 & Wyethia amplexicaule & 0.204 & -0.031 \\
\hline
\end{tabular}

\section{Discussion}

\subsection{Group and Species Preferences in a Single-Genotype Forest}

The work presented here constitutes the first complete, or baseline, survey of plant species at the iconic Pando aspen clone in central Utah, USA. The massive Pando aspen clone has likely survived for millennia [41], though as a result of recent human actions there are clearly at least three distinct plant communities supported under a genetically uniform forest canopy (Table 1). Our results also indicate distinct plant communities, interestingly, within separate fenced exclosures at Pando. Through the lens of understorey community "loyalty" (MRPP), we note that the 2014 fenced plots were statistically more similar to each other than they were to either No Fence or 2013 Fence locations (Table 1). We did not find a group distinction when the No Fence and 2013 Fence plant communities were compared to each other. Given the high rate of aspen reproduction now occurring within the 2013 Fenced exclosure [30], after only five years we must conclude that early-stage regeneration is not yet affecting plant community composition. However, light exposure to the forest floor appears to be a stronger causal factor in plant make-up at this point (Figure 2a). Our results may be describing a secondary gradient of pioneer plants 
(high diversity and light) favoring current canopy gaps and younger forests, while a shade-tolerant understorey community is tracking greater tree cover, although such conclusions seem speculative given the preliminary nature of this study.

Four species showed clear group preference (fidelity) within management areas at Pando (Table 2) and an additional three species also seem to favor specific conditions although they fell just beyond our declared statistical threshold $(p<0.05)$. Based on previous work at Pando [30,31], it is no surprise that P. tremuloides in the understorey is thriving in the 2013 Fence management area. This finding, however, is likely due more to the success of the early exclusion of browsers via fencing, then to any strictly ecological factor. Welsh et al. [36] suggest that Potentilla hippiana, Bromus ciliatus, and Artemisia tridentata favor meadows, open slopes, and partially forested (high light) habitats; thus, this fits the relatively open canopy of the 2013 Fence regime. However, similar adjacent habitat found in the No Fence zone did not show similar species fidelity leading us to wonder if perhaps low browsing level or rapid aspen regeneration are facilitating improved habitat for these species? It will be interesting to track how species composition changes over time with increased vertical complexity in recruitment facilitated by fencing. While two species favoring the 2014 Fence area have broad tolerance of light (Calamagrostis spp. and Lupinus argenteus), Silene menziesii is known to be a more shade-preferring species in montane settings [36]. Higher aspen canopy cover [31] in the 2014 Fence, alongside moderate correlations between Silene menziesii and Axis 2 (Table 4) at least partially corroborate this ISA group fidelity for shaded habitat.

Both MRPP and ISA are analyses driven solely by plant community make-up. They do not attempt to address covariation or more plainly, causation. Thus, we turned to NMS as a powerful ordination tool which combines multiple factors, alongside plant community composition, to explore causality. However, seemingly divergent results using two different analytical approaches here requires further explanation. Specifically, different species are highlighted in results of indicator species analysis (ISA; Table 2) vs. nonmetric multidimensional scaling (NMS; Figure 2b, Table 4). ISA is more pointedly directed toward discriminating between management groups based on plant communities only. While NMS (Figure 2b) may suggest alignment of certain groups in corroboration of ISA results (Table 2; i.e., P. tremuloides and Bromus ciliatus), the NMS ordination is a more comprehensive analysis taking into account an array of potential explanatory factors. In Figure 2b, the 2013 Fence plots group nicely, but the other two management group plots do not. This explains the poor performance of the variable "Fence" in the NMS final result (Table 3). Other individual species with significant correlations to the NMS (Figure 2b) align, to varying degrees with key gradients (axes), but those alignments are independent, for the most part, of group preferences exhibited in ISA results. Thus, Festuca thurberi seems to show preference for areas with higher herbivore frequency, Aquilegia caerulea and Bromus ciliatus thrive in high aspen regeneration locations, and Penstemon watsonii performs best where diversity indices are elevated (i.e., high light environments). Overall, then, we must view ISA and NMS as presenting two independent looks at habitat preferences within Pando's disparate management regimes.

\subsection{Key Factors Influence Pando's Plant Make-Up}

Human interventions, whether intended or not, have negatively affected Pando's ability to reproduce and thrive $[30,31]$. Stable aspen forests sustain themselves via relatively continuous (i.e., not episodic) recruitment; in fact, regular recruitment and a multi-story stand structure are thought to be key components of healthy stable aspen types [1,4,6,42]. Past research has described a rapidly deteriorating aspen clone resulting from increased deer and cattle herbivory, compounded by other human developments, such as added home sites, a recreational campground, and increased road traffic [35]. These features, collectively, have increased human presence and decreased mule deer hunting in a localized area to the point that the Pando grove has become a refuge from human predation, or safe-zone, for deer. Past work has shown that higher presence of deer scat related closely to higher browse level and reduced recruitment [31]. Existing monitoring data suggests that this situation 
is a prime cause of concentrated, unfettered, herbivory leading to grossly unbalanced aspen stem demographics: while mature/dying aspen are abundant, there are few recruitment stems to replace the decaying overstorey. This basic formula is clearly illustrated by key indicators opposing each other within our NMS ordination; regeneration was shown to increase on all plots where deer and cattle scat were less abundant (Figure 2a, Table 3). While this is the strongest explanatory factor presented here, it was also the central issue revealed using this data set in a previous study [35]. Browsing herbivore effects on aspen recruitment, however, are broadly implicated in the distinct understorey plant assemblages.

The addition of a detailed understorey plant survey has allowed us to not only establish group and species habitat preferences (Tables 1 and 2), but to incorporate common diversity metrics into a broader assessment of the Pando ecosystem (Tables 1 and 4; Figure 2a,b). We conclude that rapid die-off of the forest overstorey appears to be creating broad canopy openings that support relatively high understorey plant diversity. In contrast, a lack of regeneration alongside relatively high canopy cover, basal area, and total tree counts is reflected in lower diversity scores, in particular Simpson's diversity index (axis 2, Table 3; Figure 2a and Table S1). Other diversity indices corroborate a positive relationship to greater canopy openness, but our results correlate evenness negatively to Axis 1 in association with less regeneration and more herbivore presence. This evenness result is somewhat confounding to other diversity indices, but may suggest greater disparity in abundance (not richness) of species with a recent surge in aspen regeneration, most pointedly within the 2013 Fence regime group.

In terms of the explanatory value of our results, there is still much to be explored. The period since recent fencing has been erected, while inadvertently initiating divergent pathways, is likely too short for establishment of stable understorey communities (i.e., a composition in transition). Many species present, and perhaps some not yet established, may be displaying ambiguous habitat preferences at this stage within rapidly changing (e.g., 2013 Fence) environments. We also must consider the perspective of microhabitat variability -in soil types, soil depth, or terrain-inherent within even a genetically homogenous aspen clone. How would a map of native understorey variability be projected over the current human-induced larger scale compositional groupings now evident at Pando? While it may be difficult to thoroughly detect microhabitat variability with the current monitoring approach, we are still left with important questions unanswered regarding species diversity in this unique forest. Beyond plant habitat considerations, it is likely that deer (and cattle outside fences) are making preferential food choices regarding plant consumption which are affecting current understorey communities. For instance, it has been suggested that indicator plants favoring the 2014 Fence zone may be "deer resistant" and therefore are defining that (now) unique community. This assertion, if true, adds complexity to our simpler model of aspen tree canopy and structure being the key driver in defining Pando's understorey composition. While such knowledge gaps are not trivial to researchers, they also present a solid argument for management actions respective of the entire Pando system, inclusive of currently unknown explanatory features of plant diversity.

\subsection{Broader Implications for Sustained Aspen Diversity}

Much has been written about trophic implications of overabundant herbivores (e.g., [24,43]), and there is recognized disagreement on explanatory factors leading to system collapses or rebounds [44-46] that may affect aspen ecosystem diversity. At landscapes scales, diversity in aspen canopy conditions (i.e., successional stage, canopy cover, drought response, and human alterations) are expected to have concomitant implications for understorey species $[9,18]$. Here we examined a limited forest landscape, ostensibly one of unique tree species and genotypic uniformity that would be expected (if ever were the case) to have minimal variation in tree cover and thus, dependent plant communities. It may be that variation within even this limited expanse of forest encourages similar diversity, although perhaps not on the basis of spatially distinct understory plant communities. In contrast, we would anticipate that a resilient stable aspen forest (i.e., one reproducing continuously) would exhibit small-patch dynamics rather than large, human-induced, distinct vegetative communities, as appears 
to be the current situation. In fact, the present inadvertent management zones-different conditions arising from human actions affecting growth and survival-also appear to depict varying degrees of community separation based on plant composition and abundance (Tables 1 and 2). Other researchers have similarly found that herbivore effects on aspen are consequential to plant $[9,16]$, lichen [47], insect [11], and avian diversity [24], but none have examined such factors in a genetically uniform aspen forest.

Lessons gleaned from this small-scale, partially controlled (i.e., a single genotype), experiment have wider ramifications for aspen ecology and management broadly. Still, some caution is warranted in projecting our findings too far afield, given the unique nature of this large single- genotype forest. With this disclaimer broader findings from this study are as follows. First, aspen forests have traditionally been treated uniformly in terms of management prescriptions. A 1992 clearfell-coppice cutting, while appropriately protected with fencing, has resulted in a single-storied forest today. Future management actions within Pando, using the wisdom of hindsight alongside results here, would do well to manage stable aspen within functionally appropriate aspen prescriptions [4]; meaning selection and group tree felling would promote more resilient uneven-aged forests. Second, herbivory is now a common threat to survival of aspen forests, not only in North America, but across Europe as well [10,32,48,49]. Human desire for large ungulates for subsistence, aesthetics, or recreational purposes, while simultaneously eliminating key predators, in some locales, has resulted in runaway populations and concomitant vegetation impacts [43], such as the changes in understorey vegetation implicated here. In areas, undergoing rapid climate warming such as the broad region of the current study, combined effects of extended drought and herbivory are particularly detrimental to sustained aspen communities [19,24,49]. Third, we have seen here that understorey plant assemblages (and presumably dependent fauna) will be altered by aspen's response to human decisions-in cutting, recreational use, herbivore management, and other developments (i.e., roads, houses, campgrounds, and trails) —in the form of canopy openings and varying degrees of recruitment success. Human activities, overall, may also act as vectors for exotic species introductions that can have lasting effects on biodiversity in aspen communities [9]. A key resource value of aspen forests is their well-known ability to harbor a large number of plant and animal species [21,23]. In the current study area, as well as in aspen communities at scales from local to continental, we should anticipate that inappropriate management actions will have cascading effects on a rich and obligate biota. This study, focused on the single-genotype Pando forest, suggests that aspen ecosystems at-large will benefit from functionally appropriate management, prioritization of monitoring (particularly for herbivore impacts), and an understanding of critical linkages between sustainable overstorey conditions and understorey composition.

\section{Conclusions}

Previous works have demonstrated marked changes in the famed Pando aspen clone in recent decades [30,31]. We set out here to understand whether alterations in aspen overstorey and reproduction were affecting dependent plant communities. Our results indicate strong links between this unique, genetically uniform, forest and understorey species responses to recent de facto management regimes reflecting levels of canopy coverage and herbivory. We found distinct evidence that within management group species composition was more similar than across groups for two of the three pairings. Interestingly, there was greater similarity between the most successfully protected area and the completely unprotected area; this is likely a result of more open canopy covers in these two areas, whereas the third management type (2014 Fence) displayed the greatest overstorey shading. Indicator species analysis found that a small group of plant species showed statistical affinities for specific management groups, suggesting species resource preferences currently exhibited in the respective areas within Pando. Finally, an exploratory ordination analysis searching for causal factors resulted in two broad conclusions: (1) aspen regeneration, and therefore long-term resilience, is being negatively affected by chronic animal browsing and (2) current understorey species diversity is highest where 
forest canopy gaps are more abundant (i.e., where there is greater tree canopy closure, basal area, and total number of trees, there is less plant cover and richness).

We are interested in how plant species will be influenced by changing conditions at Pando over longer periods. Initial results reported here suggest Pando is moving toward a future of divergent ecological pathways despite its genetically uniform overstorey. This study constitutes a first approximation using exploratory analytical methods; repeat measures may show continued community divergence, or perhaps a convergence as structural complexity is restored at Pando. The current trajectory of increased mortality and absent successful (overall) recruitment bodes poorly for Pando's future. While greater light availability may temporarily increase plant diversity, the long- term impacts of a collapsing aspen cover are expected to decrease overall biodiversity. As a baseline study, we have documented here certain patterns that are expected to change as this forest declines or flourishes in the coming decades.

Supplementary Materials: The following are available online at http://www.mdpi.com/1999-4907/10/12/1118/s1, Table S1: Data Means \& Variances.

Author Contributions: P.C.R. conceived of the study, collected field data, obtained funding, performed analysis, and co-wrote the manuscript. J.Š. collected field data, identified plant vouchers, performed analysis, and co-wrote the manuscript.

Funding: Funding for fence construction was provided by the Secure Rural Schools program and labor came from the U.S. Forest Service, Fishlake National Forest. Additional funding for PCR provided by Utah State University Forestry Extension, Western Aspen Alliance Donation Fund, EJF Philanthropies, and the U.S. Bureau of Land Management. JŠ's participation was supported by the MENDELU International Development Project (CZ.02.2.69/0.0/0.0/16_027/0007953).

Acknowledgments: We would like to thank the U.S. Forest Service, Fishlake National Forest for their permission to conduct this research. Utah State University Ecology Center and Wildland Resources Department aided with administrative and logistical work for this study. Mensuration field work was conducted by Kasy Kliewer, Tiffany Thompson, Jody Gale, and Paul Rogers. Marc Coles-Ritchie (Grand Canyon Trust) provided review comments and suggested improvements on an earlier draft. We are grateful to the editors and anonymous reviewers for their time and experience devoted to improving this manuscript.

Conflicts of Interest: The authors declare no conflict of interest.

\section{References}

1. Betters, D.R.; Woods, R.F. Uneven-aged stand structure and growth of Rocky Mountain aspen. J. For. 1981, $79,673-676$.

2. Harniss, R.O.; Harper, K.T. Tree Dynamics in Seral and Stable Aspen Stands of Central Utah; RP-INT-297; United States Department of Agriculture Forest Service, Intermountain Research Station: Ogden, UT, USA, 1982; 7p.

3. Mueggler, W.F. Aspen Community Types of the Intermountain Region; GTR-INT-250; United States Department of Agriculture Forest Service, Intermountain Research Station: Ogden, UT, USA, 1988; 135p.

4. Rogers, P.C.; Landhäusser, S.M.; Pinno, B.D.; Ryel, R.J. A Functional Framework for Improved Management of Western North American Aspen (Populus tremuloides Michx.). For. Sci. 2014, 60, 345-359. [CrossRef]

5. Shinneman, D.J.; Baker, W.L.; Rogers, P.C.; Kulakowski, D. Fire regimes of quaking aspen in the Mountain West. For. Ecol. Manag. 2013, 299, 22-34. [CrossRef]

6. Kurzel, B.P.; Veblen, T.T.; Kulakowski, D. A typology of stand structure and dynamics of Quaking aspen in northwestern Colorado. For. Ecol. Manag. 2007, 252, 176-190. [CrossRef]

7. Franklin, J.F.; Spies, T.A.; Van Pelt, R.; Carey, A.B.; Thornburgh, D.A.; Berg, D.R.; Lindenmayer, D.B.; Harmon, M.E.; Keeton, W.S.; Shaw, D.C.; et al. Disturbances and structural development of natural forest ecosystems with silvicultural implications, using Douglas-fir forests as an example. For. Ecol. Manag. 2002, 155, 399-423. [CrossRef]

8. Holling, C.S.; Meffe, G.K. Command and control and the pathology of natural resource management. Conserv. Biol. 1996, 10, 328-337. [CrossRef] 
9. Chong, G.W.; Simonson, S.E.; Stohlgren, T.J.; Kalkhan, M.A. Biodiversity: Aspen stands have the lead, but will nonnative species take over? In Sustaining Aspen in Western Landscapes, Grand Junction, CO, USA, 13-15 June 2000; Shepperd, W.D., Binkley, D., Bartos, D.L., Stohlgren, T.J., Eskew, L.G., Eds.; RMRS-P-18; United States Department of Agriculture Forest Service, Rocky Mountain Research Station: Fort Collins, CO, USA, 2001; pp. 261-271.

10. Bartos, D.L.; Campbell, R.B.J. Water Depletion and other ecosystem values forfeited when conifer forests displace aspen communities. In Proceedings of the AWRA Specialty Conference, Rangeland Management and Water Resources, American Water Resources Association, Reno, NV, USA, 27-29 May 1998; p. 472.

11. Bailey, J.K.; Whitham, T.G. Interactions among fire, aspen, and elk affect insect diversity: Reversal of a community response. Ecology 2002, 83, 1701-1712. [CrossRef]

12. Bartos, D.L.; Campbell, R.B.J. Decline of quaking aspen in the Interior West-examples from Utah. Rangelands 1998, 20, 17-24.

13. Vehmas, M.; Kouki, J.; Eerikäinen, K. Long-term spatio-temporal dynamics and historical continuity of European aspen (Populus tremula L.) stands in the Koli National Park, eastern Finland. Forestry 2008, 82, 135-148. [CrossRef]

14. Edenius, L.; Ericsson, G. Aspen demographics in relation to spatial context and ungulate browsing: Implications for conservation and forest management. Biol. Conserv. 2007, 135, 293-301. [CrossRef]

15. Berrill, J.-P.; Dagley, C.M.; Coppeto, S.A.; Gross, S.E. Curtailing succession: Removing conifers enhances understorey light and growth of young aspen in mixed stands around Lake Tahoe, California and Nevada, USA. For. Ecol. Manag. 2017, 400, 511-522. [CrossRef]

16. Bates, J.D.; Davies, K.W. Quaking aspen woodland after conifer control: Herbaceous dynamics. For. Ecol. Manag. 2018, 409, 307-316. [CrossRef]

17. Worrall, J.J.; Rehfeldt, G.E.; Hamann, A.; Hogg, E.H.; Marchetti, S.B.; Michaelian, M.; Gray, L.K. Recent declines of Populus tremuloides in North America linked to climate. For. Ecol. Manag. 2013, 299, 35-51. [CrossRef]

18. Rogers, P.C.; Ryel, R.J. Lichen community change in response to succession in aspen forests of the Rocky Mountains, USA. For. Ecol. Manag. 2008, 256, 1760-1770. [CrossRef]

19. Rogers, P.C.; Mittanck, C.M. Herbivory strains resilience in drought-prone aspen landscapes of the western United States. J. Veg. Sci. 2014, 25, 457-469. [CrossRef]

20. Rhodes, A.C.; Wan, H.Y.; St. Clair, S.B. Herbivory impacts of elk, deer and cattle on aspen forest recruitment along gradients of stand composition, topography and climate. For. Ecol. Manag. 2017, 397, 39-47. [CrossRef]

21. Kuhn, T.J.; Safford, H.D.; Jones, B.E.; Tate, K.W. Aspen (Populus tremuloides) stands and their contribution to plant diversity in a semiarid coniferous landscape. Plant Ecol. 2011, 212, 1451-1463.

22. Kouki, J.; Arnold, K.; Martikaninen, P. Long-term persistence of aspen-a key host for many threatened species-is endangered in old-growth conservation areas in Finland. J. Nat. Conserv. 2004, 12, 41-52. [CrossRef]

23. Oaten, D.K.; Larsen, K.W. Aspen stands as small mammal "hotspots" within dry forest ecosystems of British Columbia. Northwest Sci. 2008, 82, 276-285. [CrossRef]

24. Martin, T.E. Consequences of habitat change and resource selection specialization for population limitation in cavity nesting birds. J. Appl. Ecol. 2014, 52, 475-485. [CrossRef]

25. Long, J.N.; Mock, K. Changing perspectives on regeneration ecology and genetic diversity in western quaking aspen: Implications for silviculture. Can. J. For. Res. 2012, 42, 2011-2021. [CrossRef]

26. Lindroth, R.L.; St Clair, S.B. Adaptations of quaking aspen (Populus tremuloides Michx.) for defense against herbivores. For. Ecol. Manag. 2013, 299, 14-21. [CrossRef]

27. Kemperman, J.A.; Barnes, B.V. Clone size in American aspens. Can. J. Bot. 1976, 54, 2603-2607. [CrossRef]

28. Mitton, J.B.; Grant, M.C. Genetic variation and the natural history of quaking aspen. BioScience 1996, 46, 25-31. [CrossRef]

29. DeWoody, J.; Rowe, C.A.; Hipkins, V.D.; Mock, K.E. "Pando" lives: Molecular genetic evidence of a giant aspen clone in central Utah. West. N. Am. Nat. 2008, 68, 493-497. [CrossRef]

30. Rogers, P.C.; Gale, J.A. Restoration of the iconic Pando aspen clone: Emerging evidence of recovery. Ecosphere 2017, 8, e01661. [CrossRef]

31. Rogers, P.C.; McAvoy, D.J. Mule deer impede Pando's recovery: Implications for aspen resilience from a single-genotype forest. PLOS ONE 2018, 13, e0203619. [CrossRef] 
32. Myking, T.; Bohler, F.; Austrheim, G.; Solberg, E.J. Life history strategies of aspen (Populus tremula L.) and browsing effects: A literature review. Forestry 2011, 84, 61-71. [CrossRef]

33. Schulz, B.K.; Bechtold, W.A.; Zarnoch, S.J. Sampling and Estimation Procedures for the Vegetation Diversity and Structure Indicator; PNW-GTR-781; United States Department of Agriculture Forest Service, Pacific Northwest Research Station: Portland, OR, USA, 2009; 53p.

34. McCune, B.; Lesica, P. The trade-off between species capture and quantitative accuracy in ecological inventory of lichens and bryophytes in forests in Montana. Bryologist 1992, 95, 296-304. [CrossRef]

35. McCune, B.; Grace, J.B.; Urban, D.L. Analysis of Ecological Communities; MjM Software: Gleneden Beach, OR, USA, 2002.

36. Welsh, S.L.; Atwood, N.D.; Goodrich, S.; Higgins, L.C. A Utah Flora; Brigham Young University Press: Provo, UT, USA, 1987.

37. McCune, B.; Mefford, M.J. PC-ORD: Multivariate Analysis of Ecological Data; MjM Software: Gleneden Beach, OR, USA, 2016.

38. Peck, J.E. Multivariate Analysis of Community Ecologists: Step-By-Step Using PC-ORD; MjM Sortware Design: Gleneden Beach, OR, USA, 2010.

39. Dufrêne, M.; Legendre, P. Species assemblages and indicator species: The need of a flexible asymmetrical approach. Ecol. Monogr. 1997, 67, 345-366. [CrossRef]

40. Kruskal, J.B. Nonmetric multidimensional scaling: A numerical method. Psychometrika 1964, 29, $115-129$. [CrossRef]

41. Ding, C.; Schreiber, S.G.; Roberts, D.R.; Hamann, A.; Brouard, J.S. Post-glacial biogeography of trembling aspen inferred from habitat models and genetic variance in quantitative traits. Sci. Rep. 2017, 7, 1-10. [CrossRef] [PubMed]

42. Kashian, D.M.; Romme, W.H.; Regan, C.M. Reconciling divergent interpretations of the quaking aspen decline on the northern Colorado Front Range. Ecol. Appl. 2007, 17, 1296-1311. [CrossRef] [PubMed]

43. Binkley, D.; Moore, M.M.; Romme, W.H.; Brown, P.M. Was Aldo Leopold right about the Kaibab deer herd? Ecosystems 2006, 9, 227-241. [CrossRef]

44. Beschta, R.L.; Ripple, W.J. Are wolves saving Yellowstone's aspen? A landscape-level test of a behaviorally mediated trophic cascade: Comment. Ecology 2013, 94, 1420-1425.

45. Kauffman, M.J.; Brodie, J.F.; Jules, E.S. Are wolves saving Yellowstone's aspen? A landscape-level test of a behaviorally mediated trophic cascade: Reply. Ecology 2013, 94, 1425-1431.

46. Painter, L.E.; Beschta, R.L.; Larsen, E.J.; Ripple, E. Recovering aspen follow changing elk dynamics in Yellowstone: Evidence of a trophic cascade? Ecology 2014, 329, 108-117. [CrossRef]

47. Fedrowitz, K.; Kuusinen, M.; Snäll, T. Metapopulation dynamics and future persistence of epiphytic cyanolichens in a European boreal forest ecosystem. J. Appl. Ecol. 2012, 49, 493-502. [CrossRef]

48. Edenius, L.; Ericsson, G.; Kempe, G.; Bergström, R.; Danell, K. The effects of changing land use and browsing on aspen abundance and regeneration: A 50-year perspective from Sweden. J. Appl. Ecol. 2011, 4, 301-309. [CrossRef]

49. Rogers, P.C.; Pinno, B.D.; Šebesta, J.; Albrectsen, A.; Li, G.; Ivanova, N.; Kulakowski, D.; Kusbach, A.; Kuuluvainen, T.; Landhäusser, S.M.; et al. A global view of aspen: Conservation science for widespread keystone systems. Glob. Ecol. Conserv. 2020, 21, e00828. [CrossRef]

(C) 2019 by the authors. Licensee MDPI, Basel, Switzerland. This article is an open access article distributed under the terms and conditions of the Creative Commons Attribution (CC BY) license (http://creativecommons.org/licenses/by/4.0/). 